\title{
Canada's PPE crisis isn't over yet, say doctors
}

\author{
Cite as: CMAJ 2020 May 19;192:E563. doi: 10.1503/cmaj.1095868
}

Posted on cmajnews.com on April 29, 2020

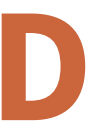
octors are calling for greater transparency about the distribution of personal protective equipment (PPE) as many report ongoing shortages of critical supplies.

"Physicians need more information about what's coming down the pipeline," said Dr. Sandy Buchman, president of the Canadian Medical Association (CMA). "When is it coming? How much is coming? Will it be good quality? Where is it being distributed?"

Governments and health facilities have scrambled in recent weeks to secure additional supplies of masks, gloves, gowns and other PPE for health workers. But these efforts do not appear to be making much difference at the front lines. According to Buchman, "physicians continue to be gravely concerned about their ability to provide care safely."

Four in 10 doctors surveyed by the CMA between April 20 and 21 said they have not seen any change in the supply of PPE over the past few weeks. A further $29 \%$ said that the situation has worsened. Close to $90 \%$ expressed some anxiety about the pandemic. According to Buchman, health workers' anxiety is "compounded by a lack of information and assurance that everything possible is being done to protect them."

Nearly 2500 doctors across Canada responded to the survey. Roughly half of the respondents work in hospitals and the rest work in the community.

The results of the poll point to some improvement in the overall supply of PPE. However, some types of equipment appear to be in shorter supply than others. On one hand, respondents were more likely to report having enough equipment to last at least 10 days compared to physicians polled by CMA in March. But when it came

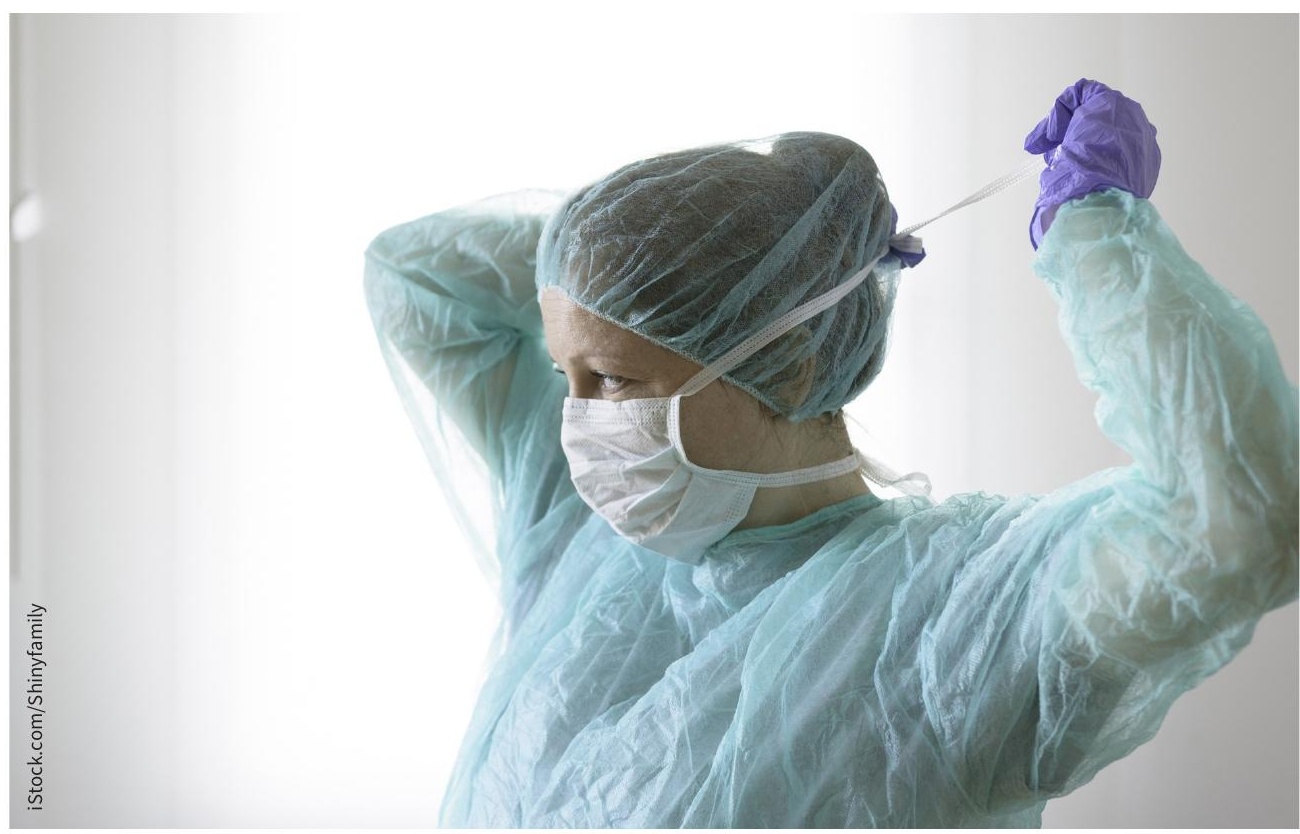

Four in 10 doctors surveyed by the Canadian Medical Association say they've seen no change in the supply of personal protective equipment.

to respirators, physicians polled this month were more likely to say they have run out of stock or will run out in two days or less.

Community physicians continue to report dire shortages; about a third of those surveyed indicated they have run out or will run out of face shields (36\%), respirators (35\%) and gowns (32\%) in two days or less.

Meanwhile, some hospital-based doctors have expressed concern about the poor quality of recent shipments of PPE, Buchman said. Others have faced "shame, blame and humiliation" for questioning the working conditions in hospitals, he said. "Does a person have a right to refuse to work if the quality of equipment provided or the safety level is inadequate? What rights do they have to protest?"

Tensions over shortages of PPE are contributing to what Buchman describes as a kind of "moral distress" among doctors. Without adequate PPE, he explained, doctors fear "they may transmit the disease to their patients or to their loved ones and families and that adds another dimension to the stress."

Buchman said the CMA is anticipating a rise in mental health issues among physicians related to the pandemic. "About 30\% were already burned out without COVID-19 so this whole situation is adding to that."

Most physicians surveyed by CMA said greater availability of PPE and increased testing for COVID-19 would ease their anxiety about the pandemic. About half also called for better virtual care options (53\%) and increased peer support (49\%).

\section{Lauren Vogel, CMAJ}

